\title{
Identifying Faculty Perceptions Of Awareness And Preparedness Relating To ADA Compliance At A Small, Private College In NE PA
}

\author{
Chad M. Stevens, Keystone College, USA \\ Elizabeth Schneider, Keystone College, USA \\ Patricia Bederman-Miller, Keystone College, USA
}

\begin{abstract}
This paper explores post-secondary faculty perceptions of awareness and preparedness relating to Americans with Disabilities Act (ADA). Institutions of higher education are businesses. The largest threat to sustained viability for many businesses is litigation. Business-related litigation is often the result of non-employment discrimination or torts (violation of civil rights). Lack of knowledge (awareness and preparedness) is usually not a sufficient reason for defendants in business-related litigation. The number of college students reporting learning-related disabilities is growing. About 2.2 million students enrolled in higher education institutions have a documented disability (National Center for Education Statistics, 2016). Disability related litigation is a trending concern for institutions of higher education. Are post-secondary faculty 'aware' and 'prepared' to make the necessary accommodations for students with qualified learning disabilities in classrooms? ADA awareness is defined as cognizance relating to the Rehabilitation Act of 1973 and Americans with Disabilities Act of 1990. ADA preparedness is defined as readiness and ability to follow obligations relating to the Rehabilitation Act of 1973 and Americans with Disabilities Act of 1990. A moderate, positive correlation was discovered between the two variables, indicating the more awareness one has of ADA laws and requirements, the more prepared one is in dealing with accommodations for those with learning disabilities. Research indicates a need for updated and current training in the area of ADA awareness and preparedness of post-secondary faculty.
\end{abstract}

Keywords: Awareness; Disability; Litigation; Post-Secondary Faculty; Preparedness

\section{INTRODUCTION}

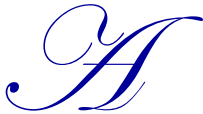

re institutions of higher education businesses? Businesses are organizations (institutions of higher education) where goods and services are exchanged for money. Businesses are public, private, forprofit, and not-for-profit. Businesses involve investment. Businesses require customers (students) (www.businessdictionary.com). About 20 million students enrolled in higher-education institutions in 2015. The average annual investment for undergraduate tuition, fees, room, and board were about $\$ 42,000$ at private non-profit institutions in 2014-2015. About 2.2 million students enrolled in higher education institutions have a documented disability (National Center for Education Statistics, 2016). Protecting investments is important for sustainability and viability for any business; including higher education institutions. The largest threat to sustained viability for many businesses is litigation. Business related litigation is often the result of non-employment discrimination or torts (violation of civil rights). Disability related litigation is a trending concern for institutions of higher education. Lack of knowledge (awareness and preparedness) is usually not a sufficient reason for defendants in business-related litigation.

The Americans with Disabilities Act ("ADA") and the Rehabilitation Act of 1973 ("Rehabilitation Act"), require virtually all U.S. colleges and universities provide reasonable accommodations to qualified disabled students. Colleges and universities are not required by law to identify, evaluate, and help students with disabilities unless a 
student asks for help and provides satisfactory proof of disability (Marklein, 2011). The determination of qualification to receive accommodations is typically left to the Disability Office at each institution of higher education, but determining whether an accommodation is "reasonable," often involves the college faculty. It is important faculty have adequate knowledge of the law as the law applies to what is considered a "reasonable accommodation." Unfortunately, faculty often indicate less than what they believe is an adequate understanding of the law in order to make appropriate decisions when addressing ADA issues (Vasek, 2005; Zang, Landmark, Reber, Hsu, Kwok \& Benz, 2010). With an ever increasing number of students entering higher education with documented disabilities, inadequate understanding becomes a problem with potentially great liability for the educational institution.

\section{BACKGROUND}

\section{Americans with Disabilities Statistics}

The U.S. Census Bureau began collecting data on disabilities in 1830. In the summer of 2012, a report by the U.S. Census Bureau indicated nearly one in five, or almost $20 \%$, of people have a disability in the U.S. In 2010, $19 \%(56.7$ million) people in the U.S. were broadly defined as disabled and over $50 \%$ of this group was 'severely' disabled. In a report entitled Americans with Disabilities: 2010, the number of disabled people increased 2.2 million (from 2005 to 2010). It is important to note, the number and percentage of people needing assistance and with severe disability increased over this same period (U.S. Census Bureau, 2016).

Disability statistics gained from The Survey of Income and Program Participation (SIPP-2010) are used by Social Security Administration, Centers for Medicare and Medicaid Services, and the Administration on Aging for program planning and management. SIPP-2010 indicated 9.4 million noninstitutionalized adults with disabilities had difficulty with at least one activity of daily living including mobility, bathing, dressing, and eating. Approximately five million needed the assistance of others. Over 15 million adults had difficulties with one or more instrumental activities of daily living (housework, using phone, preparing), with about 12 million needing assistance. Seven million people indicated frequent depression or anxiousness interfering with ordinary activities (U.S. Census Bureau, 2016).

\section{Disabilities and Education}

Postsecondary teachers (faculty) educate students in a range of academic, career, and technical subjects beyond high school at public and private colleges or universities, community-junior colleges, and technical-career institutions. Postsecondary teachers also perform research and publish intellectual papers and books (Bureau of Labor Statistics, 2016). Postsecondary teachers are often referred to as professors (assistant, associate, and full). Seven million people indicated frequent depression or anxiousness interfering with ordinary activities (U.S. Census Bureau, 2016).

According to the U.S. Department of Education, National Center for Education Statistics (2016), in the year 2011$2012,11 \%$ percent of undergraduates had a disability. A little over $20 \%$ of veteran undergraduates had a disability. Eleven to sixteen percent of undergraduates aged 23-30 reported a disability and among married independent undergraduates $13 \%-14 \%$ reported a disability. The percentage of post baccalaureate students reporting a disability in 2011-12 was 5\%. Disabilities reported by students included (one or multiple) specific learning disability, visual disability, hearing disability, speech disability, orthopedic disability, or health impairment.

Marklein (2011) reported the percentage of college students with any disability was $11 \%$. The percentage of college students with mobility, visual, or hearing problems dropped. However, the number of college students reporting learning-related disabilities is growing. The most common reported disability was attention-deficit disorders (organization and time-management) which more than tripled. Students with autism-spectrum disorders have difficulty with social skills increased substantially (Glennon, 2016). Emotional, psychological, or psychiatric conditions, at times, accompany these learning disabilities. 


\section{Post-Secondary Disability Awareness and Preparedness}

According to the Bureau of Labor Statistics (BLS) (2016), there is no consistent, if any, 'on the job' training for ADA awareness and preparedness, and in 2016 there were 1,313,000 jobs in post-secondary education with about $13 \%$ (faster than average) job outlook growth expected until 2024.

It is likely faculty will encounter students with a documented learning disability. Due to increased interaction with disabled students, faculty awareness and preparedness regarding ADA responsibilities and compliance is crucial. Faculty unawareness and unpreparedness relating to ADA responsibilities and compliance may provide a disservice to the student with the potential to lead to litigation for the educational institution.

The purpose of this research was to determine faculty perceptions of awareness and preparedness relating to faculty responsibilities and compliance with the ADA and the Rehabilitation Act. Are post-secondary faculty 'aware' and 'prepared' to make the necessary accommodations for students with qualified learning disabilities in their classrooms?

\section{Awareness and Preparedness}

Are post-secondary faculty 'aware' and 'prepared' to make the necessary accommodations for students with qualified learning disabilities in classrooms? Elementary and secondary education may provide 'special education' teachers to work with students with disabilities. There is no consistent, if any, provision of 'special education' teachers to work with disabled students in postsecondary education. Most students in higher education are provided only the assistance of some type of 'counselor.' Educational requirements for faculty in post-secondary colleges and universities vary by subject and educational institution. Most commonly, however, postsecondary teachers possess a terminal degree in a specific field of study generally with little or no training in teaching or working with students with disabilities (Bureau of Labor Statistics, 2016). Earlier studies show link between faculty knowledge of the disability laws and willingness to make the appropriate accommodations (Rao \& Garten, 2003). This link makes understanding faculty knowledge of the ADA and Rehabilitation Act so important.

Previous research indicates a positive relationship between faculty awareness and preparedness among ADA accommodation and knowledge of disability laws (Bowman \& Marzonk, 1990). Student success depends on the student/teacher match and includes teacher attitude towards students with disabilities. Attitude is partially determined by instructor awareness of disabilities and preparedness in dealing with students with disabilities (Reed, 1994). Hart and Williams (1995) assert the increasing number of college students with disabilities makes it vital for faculty to increase awareness and preparedness. In addition, faculty, administration, staff and students have a legal responsibility relating to ADA compliance (Paul, 2000).

\section{Disability Regulation}

\section{Rehabilitation Act of 1973}

Federal disability-rights laws require non-discrimination of students with learning disabilities in a post-secondary institution. Two primary federal statutes address this issue. Many states also have laws addressing educational discrimination. The Rehabilitation Act of 1973 is a federal statute including a provision prohibiting discrimination against any qualified student with a disability by a post-secondary educational institution receiving federal financial aid. Since almost all colleges and universities receive some financial aid, either directly or through students, antidiscrimination provision applies and is considered in admissions procedures, housing assignments, academic policies and other services provided to the students. Regulations promulgated pursuant to Section 504 of the Rehabilitation Act require reasonable accommodations extend to qualified students unless the institution demonstrates the accommodation sought by the student would "fundamentally alter" the program or would provide the disabled student with an advantage over other non-disabled students (Rehabilitation Act, 1973). 
Americans with Disabilities Act of 1990

Several years later, the Congress adopted the Americans with Disabilities Act of 1990 (the "ADA") and subsequent amendments, prohibiting discrimination of an otherwise qualified student based on a learning disability in a postsecondary educational institution. Under the ADA, institutions may make "reasonable accommodations" or adjustments to an academic program or to course requirements if requested by the student. The goal of the ADA is to "level the playing field" but a requested adjustment providing an advantage to the disabled student or lowering program requirements does not demand approval (Kelepouris, 2014). Some of the accommodations customarily deemed reasonable for students with learning disabilities include extended time for taking exams, submitting written papers or homework assignments, or taking exams in a quiet area. Accommodations, however, requesting different test formats or changing course or degree requirements are more difficult to approve and are almost certainly evaluated on a case by case basis (Currier, 2000). Most courts consider these two federal statues collectively when discussing what is and is not a permissible reasonable accommodation. While colleges and universities improved the educational opportunities of students with disabilities, there are still existing barriers for many students in this population (Gallego \& Busch, 2015).

\section{Case Law}

The Supreme Court did not yet decide a case outlining what is a "reasonable accommodation" in a post-secondary learning disability case. There is some guiding case law on the subject however from lower federal courts. In the seminal case of Wynne v. Tufts (1991), the First Circuit Court of Appeals established important factors to consider in determining whether a requested accommodation is reasonable. The Wynne court explained while significant deference is given to an educational institution's decision as to whether an accommodation is reasonable, the decision is not made without proper consideration of the requested accommodation, the impact on academic standards, and the program requirements. If the institution is going to deny a requested accommodation, the institution must also consider the feasibility of alternative means, and the "feasibility, cost, and effect on the academic program" or individual course requirements in order to come to a justifiable determination (Wynne, 1991).

The Wynne decision and subsequent cases require post-secondary educational institutions have a clear understanding of the essential requirements and standards for each program in order to determine whether an individual requested accommodation is "reasonable", i.e. would result in lowering those standards or markedly modifying the program. Each situation and request is considered on an individual basis and a separate analysis must be conducted (Katsiyannis, Zhang, Landmark \& Reber 2009). The same is true for requested accommodations within a specific course. With increasing numbers of students in post-secondary educational institutions with learning disabilities and the of ADA greater variety of requested accommodations, the reasonable accommodation analysis presents a continuing struggle for institutions and educators in order not to run afoul of the legal requirements.

What does this mean for faculty teaching at the post-secondary level? First, the student must follow the institution's designated disability policies for faculty to provide an accommodation. Then, a student must request an accommodation in a specific class or for a specific program requirement. According to Statistics provided by the Disabilities, Opportunities, Internetworking and Technology website through the University of Washington (Statistics, n.d.) most students reported faculty are "generally willing to provide accommodations", however, requested accommodations such as providing course substitutions, alternative assignments or different test formats were not as frequently granted (Currier, 2000). Currier (2000) recommends the student work with the faculty member directly in trying to reach a workable solution to an accommodation request. This discussion generally provides an expeditious resolution for the request and allows the student to further develop skills advocating on her/his behalf (Currier, 2000). Only if the parties cannot reach an amicable resolution, should third parties, such as the institution's disability services office, get involved. Involvement of third parties is necessary if the faculty believes the request fundamentally alters a course/program requirement or otherwise unfairly provides an advantage to the disabled student (Currier, 2000). In many cases, requests for waivers of program requirements, such as internships or fieldwork are deemed a fundamental change in the program and not granted, even for students with learning disabilities where the internship or out of class fieldwork presents a severe problem for the student (Kelepouris, 2014). 
In spite of the ADA and other legal requirements in existence for many years, faculty members have differing beliefs and understandings as to what is required. Some faculty still have concerns about how providing accommodations to some students affect other non-disabled students in the class. Other faculty have concerns over how many of the requested accommodations affect established higher-education standards and academic integrity in the classroom (Katsiyannis et al. 2009; Gallego \& Busch, 2015). In providing the legally required accommodations while still maintaining the academic freedom and high standards important in higher education, faculty need further education and training about the purpose and legal mandates of the federal disability laws to positively impact ADA awareness and preparedness (Katsiyannis et al. 2009). Post-secondary institutions also need appropriate disability policies in place and faculty need to identify the essential requirements for programs and courses to make appropriate determinations as to what requested accommodations are reasonable.

To positively impact ADA awareness and preparedness it is important all personnel involved understand the disability laws and the implications of violations of the law, including the anti-retaliation provisions, which apply when disagreements between the student and the institution or faculty arise. Since studies show many faculty and staff cite a lack of knowledge (awareness and preparedness) of the rules and regulations regarding the legal requirements (Gallego \& Busch, 2015), understanding the level of knowledge of an individual institution's faculty and staff is necessary. Providing training in the areas where a lack of awareness or preparedness and misconception arise is essential.

\section{Research Question}

1. Are post-secondary faculty aware and prepared to fulfill the requirements of providing higher education to students as outlined by the ADA?

\section{Sub-Problems}

1. What is the awareness percentage related to the ADA among post-secondary faculty at a small, private, liberal arts college in Northeastern Pennsylvania?

2. What is the preparedness percentage related to the ADA among post-secondary faculty at a small private, liberal arts college in Northeastern Pennsylvania?

3. Is there a correlation between Awareness and Preparedness of ADA requirements?

4. Do faculty feel they are aware of ADA requirements of faculty and their institution in terms of providing accommodations to students with learning disabilities?

5. Do faculty feel prepared in terms of providing accommodations to students with learning disabilities?

6. What training do faculty feel is needed in order for faculty to meet the ADA requirements for students with learning disabilities?

\section{Definitions}

ADA Awareness

ADA awareness is defined as cognizance relating to the Rehabilitation Act of 1973 and Americans with Disabilities Act of 1990 .

ADA Preparedness

ADA preparedness is defined as readiness and ability to follow obligations relating to the Rehabilitation Act of 1973 and Americans with Disabilities Act of 1990.

Post-Secondary Faculty

Post-secondary faculty is defined as faculty members employed by the institution either full-time, part-time, senior half-time or as an adjunct. 


\section{Delimitations}

Instruments were purposely chosen because of self-reporting. The distribution of form(s) through email is a delimitation. Only those with internet access were included, however, internet distribution saved time and provided convenience for both researchers and participants. Geographic location was also a delimitation, however, geographic location improved accessibility and follow-up.

\section{Limitations}

Since the sample was confined to one small, private, northeast liberal arts college, generalization was a concern. Sample size, email, and demographic restrictions impacted the power of the results. Further and more extensive research should occur to improve these boundaries. The sample may perceive they have little free time; therefore, the investment of time to participate in the study and complete the questionnaires possibly impacted participation.

Institutional administration distributed a very similar ADA survey to all relevant institutional employees, including faculty, approximately two weeks before the survey for this research was distributed. This preemptive distribution by the institution may have impacted the response rate and power of the study.

\section{Assumptions}

It was assumed post-secondary faculty were the persons completing the instrumentation. It was anticipated postsecondary faculty were honest in completing the survey. Confidentiality among participants was maintained. This addresses most of the predictive general margins of this research, however, with any research; formative situations produce additional limits.

\section{METHODOLOGY}

\section{Research Design}

This study was quantitative, non-experimental, survey research. The variables in this study were ADA awareness, ADA preparedness, and demographic.

\section{Sample}

The participants consisted of post-secondary faculty at a small northeastern Pennsylvania college. A total of 72 postsecondary faculty responded. Participants indicated consent to participate in the study by completing the ADAFQ survey.

\section{Instrumentation}

\section{ADA Faculty Questionnaire (ADAFQ)}

There was one instrument used in this study; the ADA Faculty Questionnaire (ADAFQ). The ADAFQ was adapted from several non-experimental instruments located in the research literature and therefore new (Hunter College, 2014; Hoffman, 2013; Villarreal, 2002). The ADAFQ is a takes about 7-10 minutes to complete. The ADAFQ was approved as an instrument for this study using academic and professional experts (Arcangelo \& Ullrich, 2017). This questionnaire was used to obtain demographic information such as age, gender, employment status, level of education, ADA awareness and ADA preparedness.

\section{Reliability and Validity}

The ADAFQ has content and face-validity. Experts were contacted and provided the questionnaire for review and approval. A faculty member with a doctorate in School Psychology and advanced coursework in tests and measurements, assessment practices, and teaching experience in special education including the Americans with 
Disabilities Act and Section 504 of the Rehabilitation Act of 1973, assessed the survey. A College Counselor (M.A.) and Coordinator of Disability Services also assessed the survey. Upon reviewing the ADA Faculty Questionnaire experts communicated (Arcangelo \& Ullrich, 2017):

The survey content of most questions reasonably cover the range of content related to the subject and the range of issues of interest to the study and thus appear to have content validity. Furthermore, most questions align with research are straightforward and related to the research questions.

The survey asks appropriate questions related to the content of what the research is working to assess.

Experts offered recommendations to 'wording,' section III directions and responses, and a few other recommendations reflecting current ADA conditions and survey format. Most recommendations were applied. Because the ADAFQ is new and was used for the first time there is no reliability.

\section{Procedure}

IRB approval to perform the study was obtained from the institution. Post-secondary faculty (participants) were used from a list provided by the Vice-President of Academic Affairs to the Chair of Faculty Senate. The Chair of Faculty Senate verbally announced the purpose of the research/study at two separate Faculty Senate meetings encouraging participation. Participants were contacted via institutional email at least three times over a period of two months encouraging participation. SurveyMonkey.com was used to administer the ADAFQ.

\section{Variables}

ADA Awareness

ADA awareness was measured as a 'score' using the ADAFQ. Specific questions from the ADAFQ addressing awareness included items 10-14.

\section{ADA Preparedness}

ADA awareness was measured as a 'score' using the ADAFQ. Specific questions from the ADAFQ addressing preparedness included items 15-24.

The new variables, Aware and Prepared were used in a correlation in order to determine if a relationship existed between the awareness score and the preparedness score.

\section{Analysis of Data}

Information was collected from the survey administered through Survey Monkey. The data was entered into SPSS version 25, and descriptive and inferential statistics were run. A new variable, Aware, was used to create a numeric score of faculty perception of their awareness of ADA requirements. Questions 10 through 14 were recoded as follows:

$$
2=\text { very familiar; } 1=\text { somewhat familiar; and } 0=\text { not familiar at all. }
$$

An Awareness score was determined by producing a sum of these questions. (The highest possible score was 10). The sum ranged from a low of 2 and a high of 10, with a mean of 6.2. A second variable, Prepared, was created in order to produce a Preparedness score to determine faculty's perception of how prepared they were to accommodate students with learning disabilities. Questions 15 through 24 were recoded as follows:

$$
1=\text { agree; } 0=\text { disagree, with the exception of } \# 21 \text { which used a reverse scoring of } 1=\text { disagree; } 0=\text { agree. }
$$


A Preparedness score was determined by producing a sum of these questions. (The highest possible score was 11). The sum ranged from a low of 0 to a high of 10 , with a mean of 6.3 .

\section{RESULTS}

An ADA faculty questionnaire was administered to full-time and adjunct faculty at a small, private college in Northeastern Pennsylvania. Seventy-two $(\mathrm{N}=72)$ faculty completed the survey. The sample consisted of approximately $45 \%$ full-time or senior-half time faculty with two-thirds of the sample female. About half of the responding faculty was over the age of fifty, with approximately half indicating working at the college for more than ten years. More than half of the respondents $(52.8 \%)$ were adjunct faculty, and the majority $(64.8 \%)$ indicated their highest degree at the Masters level.

When asked "Where did you receive the most information about working with students with disabilities," the majority (30\%) indicated ADA preparedness through coursework for their degree, followed by "the Office of Disability Services" (20\%). Over twenty-one percent never received information on this topic.

When given a variety of workshop choices to help preparedness to learn more about accommodating the student with disabilities, only $11.3 \%$ felt no training was needed.

When asked about what aspect of preparing their course was most challenging when dealing with student with disabilities (modifying pedagogical practices; physically altering classroom space; using assistive listening systems; adjusting deadlines; planning/providing for exams; working with students with Autism Spectrum Disorder; using assistive software; working with students with psychiatric behaviors; and "others"), all aspects of preparedness were noted as challenging. The workshop selected as needed the most was "training of policies and procedures for students with disabilities" (42.3\%).

When asked to mark what course preparations were most challenging in terms of providing accommodations to students with disabilities, all choices (modifying pedagogical practices to accommodate sensory impaired students; physically altering classroom space; adjusting assignment deadlines; planning and providing for exams; working with students with Autism Spectrum Disorder with behavioral difficulties and lacking social skills needed for the classroom; using assistive software; working with students having psychiatric disabilities which may create disruptive classroom behavior, and "other") were marked as challenging. The majority of these challenges were listed by over twenty-five percent of the respondents.

Even though over sixty percent (63.2\%) of faculty used the services of the Coordinator for Disability Services for students needing accommodations, over half $(56.5 \%)$ of respondents indicated having inadequate awareness of information about the faculty's role in facilitating access services for students with disabilities. However, almost eighty percent (79.7\%) indicated understanding and awareness of how learning disabilities affect students' learning both in and out of the classroom. Some faculty (11.6\%) indicated providing accommodations to students with documented disabilities provided an unfair advantage to disabled students and a disadvantage to the rest of the students of the class. The study also looked at the laws dealing with student disabilities to see how aware the faculty are in this area. About twenty percent were unaware with the American with Disabilities Act of 1990, while about seven percent indicated unawareness with the institution's legal obligation in providing accommodations to students with disabilities. About $13 \%$ indicated unawareness of faculty responsibilities in providing ADA accommodations for students with disabilities at the institutions, and the same percentage indicated unawareness with the process of providing testing accommodations to students with disabilities. Over four percent were unaware of the meaning of "disabilities" and how to address people with a disability.

After creating a "score" for awareness and preparedness from the faculty survey, a correlation between the two variables was run. A moderate, positive correlation, $\mathrm{r}(61)=.371, \mathrm{p}=.003$, was discovered between the two variables, indicating the more awareness one has of ADA laws and requirements, the more prepared one is in dealing with accommodations for those with learning disabilities. What is surprising is the $11.6 \%$ of faculty indicating the belief providing accommodations to students with documented disabilities provides an unfair advantage to those students and a disadvantage to the students in the rest of the class. 


\section{CONCLUSION AND RECOMMENDATIONS}

Research indicates a need for updated and current training in the area of ADA awareness and preparedness. The current research, although limited to a small, private college in Northeastern Pennsylvania illustrated the same. Looking at the results of the agree/disagree statements, and comparing them to the correct responses, indicates a need for training. It is obvious many faculty do not understand ADA laws and what is required of faculty and the institution. In addition, since some faculty (11.6\%) indicated agreement with the statement, "providing accommodations to students with documented disabilities provides an unfair advantage to those students and a disadvantage to the students in the rest of the class" also indicates a need for training and better understanding of accommodations for the learning disabled.

\section{AUTHOR BIOGRAPHIES}

Dr. Stevens has over 25 years of academic and professional experience. As a full time faculty member at Keystone College, he teaches management/administration, organizational behavior, research methods, and marketing. His research focuses on variables including emotional intelligence, cognitive/affective behavior, stress and coping, turnover, leadership styles, and awareness/preparedness in business/professional settings. His research led to the creation of a research variable; personal-career turnover (PCT). Dr. Stevens teaches undergraduate students and taught graduate students at both traditional and online higher-education institutions. His professional experience includes management and administrative positions with both national and international public companies and private practices and companies.

Attorney Elizabeth Schneider has over 30 years of private practice as a business lawyer in Pennsylvania. She is currently a full time faculty member at Keystone College and continues to maintain a small private business practice. She teaches Business Law, Business Ethics, Business Capstone, Conflict Management, Sports Law and Employment Law. She also has an MBA with a concentration in conflict management. Her research interests lie primarily with litigation avoidance and effective conflict management and resolution in business and education. Attorney Schneider teaches both undergraduate and graduate students in traditional face to face and online classes.

Dr. Bederman-Miller has over 40 years of teaching experiences in high school and college. The majority of her career was spent at the college level, teaching various mathematics courses, from basic math skills through Statistics and Research. Her research includes topics such as math anxiety, student grade perception, global citizenship, exploration of healthy eating of college students, and Supplemental Instruction (SI). Some of her current research involves faculty evaluations and online versus face-to-face statistics classes. Dr. Miller was the recipient of the 2005 Margaretta Belin Chamberlin Chair for Distinguished Faculty Service at Keystone College.

\section{REFERENCES}

Arcangelo, K. \& Ullrich, D. (2017). Expert review and assessment for content and face-validity of ADA Faculty Questionnaire $(A D A F Q)$. La Plume, PA: Keystone College

Americans with Disabilities Act (n.d.). U.S. Department of Labor. Retrieved from https://www.ada.gov/cguide.htm\#anchor65610

Bowman, O. J. \& Marzouk, D. K. (1990). Using the Americans with Disabilities Act of 1990 to empower university students with disabilities. American Journal of Occupational Therapy, 46, 450-456.

Bureau of Labor Statistics (BLS), U.S. Department of Labor (2016). Occupational outlook handbook, (2016-17 Edition), Postsecondary Teachers. Retrieved from http://www.bls.gov/ooh/education-training-and-library/postsecondaryteachers.htm

BusinessDictionary (2017). Definition of a business. Retrieved from http://www.businessdictionary.com/definition/business.html

Currier, H. (2000). The ADA reasonable accommodations requirement and the development of university services policies: Helping or hindering students with learning disabilities? 30 U. Balt. L.F. 42

Gallego, M. \& Busch, C. (2015). Towards the inclusion of students with disabilities: Accessibility in language courses. Innovative Higher Education, 40.

Glennon, T. J. (2016). Survey of college personnel: Preparedness to serve students with autism spectrum disorder. The American Journal of Occupational Therapy, 70(2)

Hart, R. D. \& Williams, D. E. (1995). Able-bodied instructors and students with physical disabilities: A relationship handicapped 
by communication. Communication and Education, 44, 140-154.

Hoffman, J. F. (2013). Disability: Faculty knowledge, awareness, and perceptions. California State University, Long Beach, ProQuest Dissertations Publishing, 3574918.

Hunter College, (2014). Office of Accessibility-Student Services Faculty Disability Awareness Survey. Retrieved from http://www.hunter.cuny.edu/access/repository/files/faculty-survey-answer-sheet.pdf

Katsiyannis A., Zhang, D, Landmark, L., \& Reber, A. (2009). Postsecondary education for individuals with disabilities. Journal of Disability Policy Studies, 20(1)

Kelepouris, C. (2014). Transitioning students with disabilities into higher education. BYU Educ. \& L. J. 27.

Marklein, B. (2011). Learning disabled students get firmer grip on college. USA Today. Retrieved from http://usatoday30.usatoday.com/news/education/story/2011-10-17/college-and-learning-disabilities/50807620/1

Paul, S. (2000). Students with disabilities in higher education: A review of the literature. College Student Journal, 34(2), 200-210

Projections Central (2016). State occupational projections. Retrieved from http://www.projectionscentral.com/Projections/ShortTerm

Rao, S. \& Gartin, B. C. (2003). Attitudes of university faculty toward accommodations to students with disabilities. Journal for Vocational Special Needs Education, 25(2).

Reed, M. M. (1994). Assessing the needs of university faculty who teach students with disabilities. Doctoral dissertation, Georgia State University.

Rehabilitation Act (1973). U.S. Department of Labor. Retrieved from https://www.ada.gov/cguide.htm\#anchor65610

Statistics. (n.d.). Retrieved February 26, 2016, from http://washington.edu/doit/statistics

United States Census Bureau. (2016). Survey of income and program participation. Retrieved from http://www.census.gov/programs-surveys/sipp/data.html

U.S. Department of Education, National Center for Education Statistics (2016). Digest of education statistics, 2014 (2016-006), Chapter 3.

Vasek, D. (2005). Assessing the knowledge base of faculty at a private, four-year institution. College Student Journal. 39(2).

Villarreal, P. (2002). Faculty knowledge of disability law: Implications for higher education practice. Waco, TX: Baylor University.

Wynne v. Tufts Univ. Sch. of Med., 932 F.2d 19, 21 (1st Cir. 1991)

Zang, D, Landmark, L., Reber, A, Hsu, H., Kwok, O. \& Benz, M. (2010). University faculty, beliefs, and practices in providing reasonable accommodations to students with disabilities. Remedial and Special Education. 31(4). 


\section{APPENDIX A}

\section{ADA Faculty Questionnaire}

Dear Colleague:

Many colleges are seeing an increase of the number of students with a documented disability. Research indicates post-secondary faculty awareness and preparedness of the ADA is subject for concern. Therefore, you are invited to participate in a research study among Keystone College faculty regarding ADA compliance and student disabilities.

This brief multiple-choice survey is anonymous; it should take approximately 15 minutes or less to complete.

Please feel free to contact Chad Stevens, Ph.D. (570-945-8431); Elizabeth Schneider, J.D. (570-945-8423); or Patricia Bederman Miller, Ph.D. (570-945-8401) with any questions or comments about the survey.

I. For each of the following, please click the response that best describes you.

1. My gender:

Male___ Female

2. My age range:
$21-30$
$31-40$
$41-50$
$51-60$
61 or older

3. My current employment at this institution is:

Full-time

Senior Part-Time

Adjunct

4. Number of years I worked as a faculty member at this institution:
$0-5$ years
6-10 years
$11-15$ years
16-20 years
over 20 years

5. My highest degree is:

- Bachelor's degree

- Master's degree

- Doctorate

o Other:

6. My current faculty status is:
Professor
Associate Professor
Assistant Professor
Instructor
Adjunct
Other

7. Where did you receive the most information about working with students with disabilities?
While taking coursework for my degree (BS/BA, Master's degree, Doctoral Degree)
During New Faculty and Adjunct Orientation
In Departmental meetings
Through the Office of Disability Services
In Faculty workshops
Other (please specify)
I never received information on this topic

Copyright by author(s); $\underline{\text { CC-BY }}$ 
8. Given classroom experiences with students with disabilities, what aspects of your course(s) do you find most challenging in terms of providing accommodations? Please select all that apply.

- Modifying my pedagogical practice to accommodate sensory impaired students (Deaf, hard-of-hearing, vision impaired, blind)

- Physically altering my classroom space to accommodate a wheelchair user, a student who requires a special desk and chair, or a note taker

$\circ \quad$ Using an assistive listening/FM loop system device for a hard-of-hearing student

- Adjusting assignment deadlines for students with learning disabilities, memory/concentration limitations, or other cognitive accommodations

- Planning, and providing for, exams for students with accommodations

- Working with students with Autism Spectrum Disorder, who may demonstrate behavioral difficulties or lack of proper social skills in the classroom

- Using assistive software as a tool in the classroom, to better accommodate students with disabilities

- Working with students with psychiatric disabilities, who may exhibit disruptive behavior in the classroom or other behavioral difficulties.

$\circ \quad$ Other (please specify)

9. Which of the following workshops would you find most helpful in assisting you to accommodate students with disabilities? (Choose all that apply)

- Using technology to teach students with disabilities

Using a Universal Design in instruction

Working with students with basic reading, writing, and math disabilities

Working with students with behavioral difficulties

Working with students with Autism Spectrum Disorder

Working with students with ADHD

Training on ADA and 504 regulations

Training on the policies and procedures for students with disabilities

Teaching Deaf or hard-of hearing students

Other (please specify)

I do not feel I need training on this subject

II. Please indicate how familiar you are with each of the following.

10. How familiar are you with the American with Disabilities Act of 1990 as amended by the ADA Amendments Act of 2008, and Section 504 of the Rehabilitation Act of 1973?

- Very familiar

- Somewhat familiar

○ Not familiar at all

11. How familiar are you with the institution's legal obligation in providing accommodations to students with disabilities?
Very familiar
Somewhat familiar
Not familiar at all 
12. How familiar are you with your responsibilities as a faculty member for providing 504/ADA accommodations for Students with Disabilities at our institution?
- Very familiar
Somewhat familiar
- Not familiar at all

13. How familiar are you with the process of providing testing accommodations to students with disabilities?
○ Very familiar
- Somewhat familiar
- Not familiar at all

14. How familiar are you of the meaning of "disabilities" and on how to address people with a disability:
○ Very familiar
- Somewhat familiar
- Not familiar at all

III. For each of the following, please indicate if you agree or disagree.

15. Faculty in higher education are required to provide an accommodation to a student with a disability even if the student does not request it.
- Agree
- Disagree

16. A student registering a disability with the Coordinator of Disability Services may choose whether to disclose the nature of her/his disability, or need for accommodations, to faculty members.
- Agree
○ Disagree

17. A classroom location should be changed to meet the needs of students with disabilities, when the assigned classroom is not fully accessible.
- Agree
○ Disagree

18. Instructors may use their own discretion in deciding not to provide extended time as a form of accommodation to a student with a disability.
- Agree
$\circ$ Disagree

19. Sign language interpreters/note-takers/classroom assistants may attend class even when a student is absent to relay class information. 1
- Agree
$\circ$ Disagree 
20. Classroom assistants (Sign Language Interpreters, Note-takers, etc.) may actively participate in class discussions and offer their own opinions.
- Agree
- Disagree

21. Faculty may discuss students' progress with faculty/staff/classroom assistants without the student present.
- Agree
○ Disagree

22. I have an adequate information about the faculty's role in facilitating access services for students with disabilities.
- Agree
○ Disagree

23. I used the services of the Coordinator for Disability Services in regards to my students needing accommodations.
- Agree
$\circ$ Disagree

24. I understand how learning disabilities affect students' learning both in, and out, of the classroom.
- Agree
$\circ$ Disagree

25. Providing accommodations to students with documented disabilities provides an unfair advantage to those students and a disadvantage to the students in the rest of the class.
○ Agree
$\circ$ Disagree

Thank you for participating in this survey. Please feel free to include any suggestions/comments in the space provided below. 